\title{
Acyclovir prophylaxis of recurrent genital herpes: randomised placebo controlled crossover study
}

\author{
G R KINGHORN,* M JEAVONS,* M ROWLAND,* I ABEYWICKREME,* I G BARTON, $\dagger$ \\ $\mathrm{C} W$ POTTER, $\dagger$ AND E A HICKMOTT $\ddagger$
}

From the *Department of Genitourinary Medicine, Royal Hallamshire Hospital, Sheffield, the $\dagger$ Department of Virology, Medical School, University of Sheffield, and the $\ddagger$ Clinical and Applied Research Division, Wellcome Foundation, Beckenham, Kent

SUMMARY Forty patients were entered into a randomised placebo controlled crossover study to assess the efficacy and safety of oral acyclovir $200 \mathrm{mg}$ four times a day in the prophylaxis of recurrent genital herpes. Each treatment began during a recurrence and continued for a maximum of 84 days or until the onset of the next recurrence, when the alternate medication was started. Of 28 patients who completed both treatment courses, only three developed a recurrence while taking acyclovir compared with 26 while taking placebo. The mean time to first recurrence was more than 84 days in patients receiving acyclovir and 24 days in patients receiving placebo $(p<0.001)$. The mean time to first recurrence after treatment with acyclovir ceased was 16 days. Adverse events, though thought unlikely to be related to treatment, necessitated the withdrawal from the study of two patients while taking acyclovir and one patient while taking placebo. No clinically important effects on haematological or biochemical variables occurred during the acyclovir treatment. All viral isolates tested after treatment remained sensitive to acyclovir. Acyclovir prophylaxis of recurrent genital herpes is effective and safe but does not appear to influence the natural history of the disease after cessation of 84 days' continuous treatment.

\section{Introduction}

Though short courses of acyclovir, used in intravenous, ${ }^{12}$ oral, ${ }^{3-5}$ and topical formulation $s^{6-10}$ are of clinical benefit in treating first and recurrent episodes of genital herpes, they do not appear to influence the incidence of future recurrences. Acyclovir prophylaxis of herpes simplex virus (HSV) infections has been successfully used in immunocompromised patients; ${ }^{11-15}$ recent studies in immune competent patients have also shown an appreciably reduced incidence of genital recurrences in parallel groups of patients treated with continuous oral acyclovir compared with placebo. ${ }^{16-18}$

In this randomised double blind crossover study our objective was to compare in the same patients the efficacy and safety of continuous oral acyclovir with

Address for reprints: Dr G R Kinghorn, Consultant in Genitourinary Medicine, Royal Hallamshire Hospital, Glossop Road, Sheffield S10 2JF

Accepted for publication 12 April 1985 apparently identical placebo in preventing recurrences of genital herpes.

\section{Patients and methods}

STUDY POPULATION

Men and women aged 18 or more attending the department of genitourinary medicine, Royal Hallamshire Hospital, Sheffield, who had had six or more recurrences of genital herpes in the preceding year were eligible for the study; patients who were enrolled had experienced at least one documented culture positive episode in the preceding two months. All patients had normal renal and hepatic function and none had received recent antiviral or immune stimulatory treatment. Women who were pregnant or using inadequate contraception were excluded.

\section{STUDY DESIGN}

Patients were entered into the study within 72 hours of the onset of a recurrence. They were randomly allocated to a first treatment course consisting of 
either acyclovir $200 \mathrm{mg}$ or matching placebo tablets taken four times a day. Medication was prescribed in bottles containing 28 days' supply of tablets, and the maximum duration of the treatment course was 84 days. Patients were asked to return to the clinic at the onset of their next recurrence, when they were given the alternate medication. If they had remained free of recurrences throughout the first 12 week treatment period, the start of the crossover treatment was delayed until the onset of the next recurrence. Thus each treatment was started at the onset of a recurrence. The efficacy of each treatment was assessed by comparing the time to first recurrence while the patient was taking acyclovir tablets with the corresponding time to first recurrence while taking placebo tablets.

\section{PATIENT ASSESSMENT}

At each patient's entry to the study and on subsequent attendances a history was taken, clinical examination was performed, specimens for viral culture were obtained, and blood and urine specimens were collected for toxicity testing. During the whole duration of the study patients were requested to complete a daily diary card of symptoms and to record the number of tablets taken. Follow up appointments were arranged at intervals of a maximum of four weeks. Compliance with treatment was then assessed by counting the number of residual tablets. Specimens for viral culture were taken routinely from the urethra of men and cervix of women and from any clinically suspect genital herpetic lesion. Routine toxicity testing consisted of urine analysis for blood, protein, and glucose and analysis of blood for haematological variables, biochemical testing for urea, creatinine, and electrolytes, and for liver function tests.

\section{VIRUS ISOLATION}

The collection and transport of specimens for viral culture and the laboratory techniques of viral isolation and typing have been described previously. ${ }^{10}$ When isolates could be retrieved (before, during, or after acyclovir treatment), these were sent to the Wellcome Research Laboratories for acyclovir sensitivity testing. The results were expressed as $\mathrm{IC}_{50}$ (the concentration $(\mathrm{mg} / \mathrm{l})$ of the drug required to reduce plaque by $50 \%$ ).

\section{STATISTICAL TECHNIQUES}

The time to first recurrence while receiving each treatment was compared by the Sign test. The time to recurrence while receiving placebo was compared with the time to recurrence after receiving acyclovir by Wilcoxon's rank sum test.

For analysis of the blood test results a statistical investigation of the percentage abnormal measurements during each treatment was carried out using the Sign test. Mean values for each variable were analysed by fitting a linear model to the data using maximum likelihood estimation in which the effects due to sex, treatment and its duration, and patient differences were considered.

\section{Results}

NUMBER OF PATIENTS AND THEIR CHARACTERISTICS From a total of 40 patients ( 24 men and 16 women) enrolled into the study, 28 (16 men and 12 women) completed the scheduled treatment with both acyclovir and placebo.

Of the 12 patients who were excluded from the efficacy analysis, six defaulted from follow up (three while taking acyclovir, three while taking placebo), one was withdrawn because of failure to comply with the protocol, two did not experience a subsequent recurrence during the study period after completing their first treatment period (one after taking acyclovir, the other after taking placebo), and three were withdrawn after the development of adverse events during treatment (two taking acyclovir, one taking placebo).

The mean age of entrants to the study was 29.4 (range 18 to 52 ) years, the median number of yearly recurrences was 12 (range six to 40), and the median duration of genital herpes before enrolment was three (range one to 12 years).

HSV 2 isolates were obtained from 38 patients and HSV 1 from three patients; one patient yielded both HSV 2 and HSV 1.

\section{EFFICACY OF ACYCLOVIR}

Two of the 28 patients who completed the trial did not experience a recurrence while being treated with either acyclovir or placebo. The other 26 patients experienced a recurrence while receiving placebo, and only three of them experienced a recurrence while receiving acyclovir (table I). In two of these patients the failure to comply with medication was a contributory factor initiating recurrence: in one a recurrence developed five days after supplies of medication ran out while she was on holiday, in the

TABLE I Number (\%) of patients experiencing recurrence of genital herpes during trial

\begin{tabular}{llll}
\hline & \multicolumn{2}{c}{ Patients receiving: } & \\
\cline { 2 - 3 } & \multicolumn{1}{c}{ Acyclovir } & Placebo & Difference \\
\hline $\begin{array}{l}\text { Patients receiving acyclovir } \\
\text { first }(\mathrm{n}=16)\end{array}$ & $2(13)$ & $15(94)$ & $\mathrm{p}<0.001$ \\
$\begin{array}{l}\text { Patients receiving placebo } \\
\text { first (n = 12) }\end{array}$ & $1(8)$ & $11(92)$ & $\mathrm{p}<0.001$ \\
All patients $(\mathrm{n}=28)$ & $3(11)$ & $26(93)$ & $\mathrm{p}<0.001$ \\
\hline
\end{tabular}


other compliance assessment showed that a large number of tablets had not been taken.

In all patients, the mean time to first recurrence was significantly $(\mathrm{p}<0.001)$ longer while they were taking acyclovir, irrespective of whether this was the first or second course of treatment (table II).

TABLE II Median number of days to first recurrence

\begin{tabular}{llll}
\hline & \multicolumn{2}{l}{ Days taking: } & \\
\cline { 2 - 3 } & \multicolumn{1}{c}{ Acyclovir } & Placebo & Difference \\
\hline $\begin{array}{l}\text { Patients receiving acyclovir } \\
\text { first }(\mathrm{n}=16)\end{array}$ & $>84$ & 28 & $\mathrm{p}<0.001$ \\
$\begin{array}{l}\text { Patients receiving placebo } \\
\text { first (n }=12)\end{array}$ & $>84$ & 22 & $\mathrm{p}<0.001$ \\
\begin{tabular}{l} 
All patients $(\mathrm{n}=28)$ \\
\hline
\end{tabular} & $>84$ & 24 & $\mathrm{p}<0.001$ \\
\hline
\end{tabular}

Of the 25 patients who completed the acyclovir treatment course without experiencing a recurrence, all but one had a recurrence in, the year after discontinuing treatment. The median time to first recurrence after taking acyclovir was $\mathbf{1 6}$ days (range two to 160 days). The figure shows survival analysis

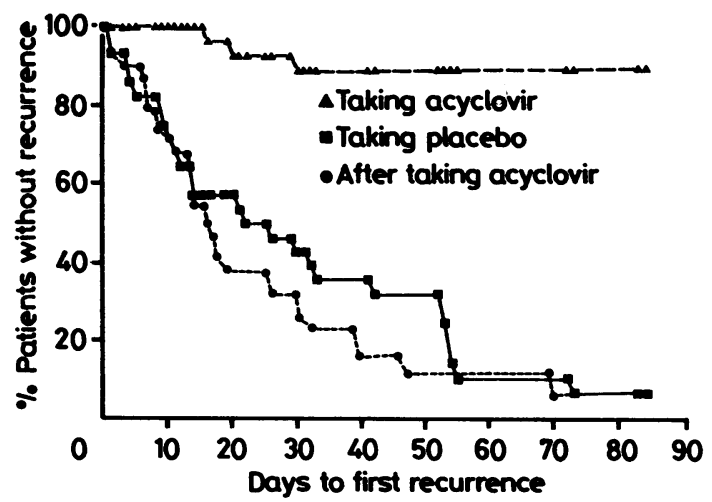

FIGURE Prophylactic treatment of recurrent genital herpes with oral acyclovir

curves for the times to first recurrence while taking acyclovir or placebo and after discontinuing acyclovir. There was no significant difference in the median times to first recurrence for all patients while taking placebo compared with after acyclovir treatment (table III).

\section{ADVERSE EVENTS AND TOXICITY TESTING}

Adverse events were reported by eight patients during acyclovir treatment and two patients during placebo treatment.

A woman with a history of ankle swelling developed throbbing discomfort in both calves and unilateral
TABLE III Median number of days to first recurrence

\begin{tabular}{llll}
\hline & \multicolumn{2}{l}{ Days: } & \\
\cline { 2 - 3 } & $\begin{array}{l}\text { After } \\
\text { taking } \\
\text { acyclovir }\end{array}$ & $\begin{array}{l}\text { Taking } \\
\text { placebo }\end{array}$ & Difference \\
\hline $\begin{array}{l}\text { Patients receiving acyclovir } \\
\text { first (n = 14) }\end{array}$ & 11 & 38 & $\mathrm{p}<0.01$ \\
$\begin{array}{l}\text { Patients receiving placebo } \\
\text { first (n }=11)\end{array}$ & 19 & 22 & $\mathrm{p}<0.1$ \\
\begin{tabular}{l} 
All patients $(\mathrm{n}=25)$ \\
\hline
\end{tabular} & 16 & 30 & $\mathrm{p}<0.07$ \\
\hline
\end{tabular}

ankle oedema after taking acyclovir for two days. Treatment was temporarily stopped while a venogram was performed, which excluded deep, venous thrombosis as the cause of her symptoms. When acyclovir was recommenced, the same symptoms recurred after three days; treatment was the terminated. A man asked to be withdrawn from the study while taking acyclovir because of persistent headache, joint pains, and sore eyes; clinical examination showed no abnormality, and his symptoms were not thought to be related to the treatment. Transient episodes of penile discomfort or erythema and flatulence, or all three, were reported by two patients, of drowsiness by one patient, and of conjunctivitis by one patient. These conditions resolved despite continuation of acyclovir.

During placebo treatment, one patient was withdrawn from the study when severe depression developed. Transient conjunctivitis occurred in another patient.

A statistical analysis of blood chemistry and haematology data showed no significant differences in the occurrence of abnormal measurements recorded for each treatment group. Though there were significantly lower total protein concentrations $(\mathrm{p}=$ $0.04)$ and red cell counts $(p=0.03)$ and a trend towards higher erythrocyte sedimentation rates $(\mathrm{p}=$ 0.09 ) when acyclovir was used, the differences between mean values, which remained well within their normal ranges, were small and not considered to be of clinical importance.

VIRAL SENSITIVITIES BEFORE AND AFTER TAKING ACYCLOVIR

Viral isolates were tested before and after patients took acyclovir. In 10 patients both sets of isolates remained within the expected range for sensitive virus $\left(\mathrm{IC}_{50}<2 \mathrm{mg} / \mathrm{l}\right)$. In a further six patients from whom viral isolates were tested only after taking acyclovir, the $\mathrm{IC}_{50}$ also remained $<2 \mathrm{mg} / \mathrm{l}$.

\section{Discussion}

The results of this crossover study show that 
continuous oral acyclovir $\mathbf{2 0 0} \mathrm{mg}$ four times a day is effective in preventing recurrent genital herpes. They confirm other recent reports in which efficacy was assessed by comparisons between parallel groups of patients treated with either acyclovir or placebo. ${ }^{15-18}$ Only three of 28 of our patients developed recurrences during acyclovir treatment; in all three patients viral isolates after treatment remained sensitive to acyclovir. In two of the apparent treatment failures there was evidence of compliance problems; and in both of these patients, who were subsequently entered into an open study, acyclovir has been completely effective in suppressing recurrences for 12 months when given in the same dosage. Successful treatment with acyclovir for periods of $\mathbf{8 4}$ days, however, does not affect the natural history of the disease once treatment is discontinued. The time to first recurrence after treatment with acyclovir was similar to that in patients who were taking placebo.

Prophylactic treatment with acyclovir was not associated with serious side effects. No definite causal relation was established between acyclovir and adverse events necessitating withdrawal of the drug. Though statistical analysis of blood chemistry and haematological data showed appreciably lower total protein concentrations and red blood cell counts when acyclovir was used, this does not necessarily imply clinical importance. Mean values for these variables remained within the normal ranges for our laboratories. Furthermore, for a study of this size at least one result may be expected to attain statistical significance purely by chance, and it is possible that the observed differences may be unrelated to treatment.

Concern has been expressed about the possible emergence or selection of acyclovir resistant viruses during prophylactic treatment. ${ }^{17-20}$ We found that all isolates taken before treatment with acyclovir were fully sensitive to the drug, and that isolates taken after treatment showed no appreciable change in sensitivity to acyclovir. Nevertheless, it would seem wise to advocate that selected centres should continue sensitivity testing of viral isolates from patients undergoing long term acyclovir prophylaxis to investigate further this possibility.

In summary, we have confirmed the efficacy and safety of oral acyclovir prophylaxis of recurrent genital herpes. As treatment for up to 12 weeks does not appear to influence the natural history of genital herpes once the drug has been discontinued, studies to assess efficacy and safety during and after longer courses of acyclovir are desirable. The present high cost of maintenance treatment with oral acyclovir is likely to preclude its usefulness in all but those patients who are severely incapacitated by very frequent recurrences.
We thank Dr A P Fiddian, Mrs C Burke, and Mr D Jones of the Wellcome Foundation for their advice and help with this study, and Mrs L Arnold for typing the manuscript.

\section{References}

1. Mindel A, Adler MW, Sutherland S, Fiddian AP. Intravenous acyclovir treatment for primary genital herpes. Lancet 1982;is697-700.

2. Corey, L, Fife KH, Benedetti JK, et al. Intravenous acyclovir for the treatment of primary genital herpes. Ann Intern Med 1983;98:914-21.

3. Nilsen AE, Aasen R, Halsos AM, et al. Efficacy of oral acyclovir in the treatment of initial and recurrent genital herpes. Lancet 1982;ii:571-3.

4. Bryson YJ, Dillon $M$, Lovett $M$, et al. Treatment of first episodes of genital herpes simplex virus infection with oral acyclovir. A randomised double blind controlled trial in normal subjects. N Engl J Med 1983;308:916-21.

5. Salo OP, Lassus A, Hovi T, Fiddian AP. Double blind placebo controlled trial of oral acyclovir in recurrent genital herpes. European Journal of Sexually Transmitted Diseases 1983;1:958.

6. Corey L, Nahmias AJ, Guinan ME, Benedetti JK, Critchlow CW, Holmes KK. A trial of topical acyclovir in genital herpes simplex virus infection. N Engl J Med 1982;306:1313-9.

7. Thin RN, Nabarro JM, Parker JD, Fiddian AP. Topical acyclovir in the treatment of initial genital herpes. British Journal of Venereal Diseases 1983;59:1 16-9.

8. Reichman RC, Badger GJ, Guinan ME, et al. Topically administered acyclovir in the treatment of recurrent herpes simplex genitalis: a controlled trial. J Infect Dis 1983;147:33640.

9. Fiddian AP, Kinghorn GR, Goldmeier D, et al. Topical acyclovir in the treatment of genital herpes: a comparison with systemic therapy. J Antimicrob Chemother 1983;12suppl B:6777.

10. Kinghorn GR, Turner EB, Barton IG, Potter CW, Burke CA Fiddian AP. Efficacy of topical acyclovir cream in first and recurrent episodes of genital herpes. Antiviral Res 1983;3: 21301.

11. Saral R, Burns WH, Laskin OL, Santos GW, Lietman PS Acyclovir prophylaxis of herpes simplex virus infections. A randomised double blind controlled trial in bone marrow transplant recipients. N Engl J Med 1981;305:63-7.

12. Anderson H, Scraffe JH, Sutton RNP, et al. Oral acyclovi prophylaxis against herpes simplex virus in non-Hodgkins lymphoma and acute lymphoblastic leukaemia patients receiving remission induction chemotherapy: a randomised double blind, placebo controlled trial. $B r J$ Cancer 1984;50/1:45-9.

13. Saral R, Ambinder RF, Burns WH, et al.Acyclovir prophylaxis of herpes simplex virus infection in patients with leukaemia. Ann Intern Med 1983;99:773-6.

14. Prentice HG. Use of acyclovir for prophylaxis of herpes infections in severely immunocompromised patients. $J$ Antimicrob Chemother 1983;12 suppl B:153-60.

15. Gluckman $E$, Lotsberg J, Devergie A, et al. Oral acyclovir prophylactic treatment of herpes simplex infection after bone marrow transplantation. J Antimicrob Chemother 1983;12 suppl B:161-7.

16. Mindel A, Faherty A, Hinley D, et al. Prophylactic oral acyclovir in recurrent genital herpes. Lancet 1984;itis7-9.

17. Douglas JM, Critchlow C, Benedetti J, et al. A double blind study of oral acyclovir for suppression of recurrences of genital herpes simplex virus infection. $N$ Engl J Med 1984;310:1551-6.

18. Straus SE, Takiff HE, Seidlin M, et al. Suppression of frequently recurring genital herpes. A placebo controlled double blind trial of oral acyclovir. N Engl J Med 1984;310:1545-50.

19. Crumpacker CS, Schnipper BJ, Marlowe SI, Kowalsky PN, Hershey BJ, Levin MJ. Resistance to antiviral drugs of herpes simplex virus isolated from a patient treated with acyclovir. $N$ Engl J Med 1982;306:343-6.

20. Burns WH, Saral R, Santos GW, et al. Isolation and characterisation of resistant herpes simplex virus after acyclovir therapy. Lancet 1982; i $421-3$. 